\title{
The development impact of solar cookers: A review of solar cooking impact research in South Africa
}

\section{Marlett Wentzel $^{\mathrm{a}}$ and Anastassios Pouris ${ }^{\mathrm{b}, 1}$}

${ }^{\mathrm{a}}$ Institute for Technological Innovation, Faculty of Engineering, Built Environment and Information Technology, University of Pretoria, PO Box 11906, Queenswood, Pretoria 0121, South Africa

${ }^{\mathrm{b}}$ Institute for Technological Innovation, Faculty of Engineering, Built Environment and Information Technology, Room 7-15 Engineering 1 Building, EBIT Faculty, University of Pretoria, Lynwood Road, South Africa

\begin{abstract}
Solar cooking is often considered “a solution looking for a problem”. Solar cookers have long been presented as an interesting solution to the world's problem of dwindling fuel wood sources and other environmental problems associated with wood fuel demand for cooking. However, recent GTZ field work in South Africa showed different benefits instead: the use of solar cookers resulted in appreciable fuel and time savings as well as increased energy security for households using commercial fuels. These observations are based on field tests in South Africa that started in 1996 to investigate the social acceptability of solar cookers and to facilitate local production and commercialisation of the technology. Impact studies and use rate studies have been carried out by a number of different organisations since the inception of the project and although commercialisation of the technology has not been achieved to its fullest potential, impact studies indicate that solar cookers have a positive development impact on households through fuel-, energy- and time savings. The article aims to summarise the findings of the various studies and present an overview of use rates and impact data. A variety of factors influence solar cooker use rates, which in turn determine impacts. Some factors are
\end{abstract}


related to the user, some to the environment in which the cooker is used and some to the cooker itself. Ultimately, the data shows that on average, only $17 \%$ of solar cooker owners do not use their stoves after purchase and that active solar cooker users utilise their stoves on average for $31 \%$ of their cooking incidences. Since the majority of solar stove buyers actually use their stoves and obtain real benefits, this suggests that that solar cookers are indeed not a solution looking for a problem but a solution worth promoting.

\section{Article Outline}

1. Introduction

2. Solar cooking history

3. Motivation for promotion of solar cookers

4. The GTZ/DME solar cooker field test in South Africa

5. The development impact of solar cookers

5.1. Solar cooker use rates

5.1.1. External conditions

5.1.2. Change in interest

5.1.3. Stove characteristics

5.1.4. Lack of black cooking pots

5.2. Savings associated with solar cooker use

5.2.1. Fuel savings

5.2.2. Monetary savings

5.2.3. Time savings

5.2.4. Impacts on poverty reduction

5.2.5. Income generation potential of solar cookers

6. Conditions promoting the use of solar cookers

6.1. External or environmental conditions

6.2. User conditions

6.3. Technical conditions of solar cookers

7. Conclusions and recommendations

Further Reading

References 


\section{Introduction}

Solar cooking has regularly been viewed as a solution looking for a problem, or a technological solution developed without sensitivity to user needs. It has been described as a solution pushed on consumers who demonstrate their enthusiasm for the devices by keeping them under their beds or using it for storage of clothes and other household items. Although there are many cases where such criticism may be valid, recent attempts to introduce, demonstrate and test solar cookers are moving away from a technologicaldriven approach where a solar cooker is offered to consumers as the ultimate solution to all their cooking needs. Specific reference is made here to the activities of the DME/GTZ solar cooker field test executed in South Africa from 1996 which concluded, “Many advancements have been made in the technical advancement of solar cookers, but unfortunately, very little attention has been paid to the social context, as defined by the needs of the potential users. Unless the technical aspects are accommodated to the people's needs, the solar cooking technology will never be able to gain any real extent of popularity”. Other initiatives in Niger, Burkina Faso (see for example the work of the Kozon Foundation www.kozon.org) and Nepal (Shrestha et al., 2005) as well as the efforts of Solar Cookers International in Africa also display a new awareness of placing consumer needs and priorities ahead of technical considerations and to promote solar cooking as part of an integrated solution to cooking problems. Although results remain mixed, important lessons are emerging from recent efforts:

- solar cookers are no longer presented as a total solution to cooking problems. They are being promoted as an add-on cooking device with specific potential benefits and offering more choice and flexibility to consumers whom are normally forced to use specific fuels or appliance combinations because of affordability and accessibility issues. In other words, consumers are not lead to believe that solar cookers will replace their wood burning stoves, but rather, that there are appropriate opportunities and specific conditions under which solar cookers offer the most benefits. Consumer choice becomes the focuswhich stove or cooking device is the best to use under different circumstances;

- in the South African field test, solar cookers were not offered as a stand-alone cooking solution but as part of an integrated cooking package, including a fuel efficient stove and

a heat retention device. By offering a modular, package option, consumers could buy the 
complete package or just the device that they feel may have the most benefit to them. They may then later obtain other devices in the package. Importantly, they are offered choice, they are exposed to a number of workable solutions to achieve fuel savings and they can build confidence in the product range;

- most programmes and projects have realised that designing the perfect solar cooker will not result in massive take-up of the technology. Historically, inventors chased the “perfect cooker”, always assuming that if they can design the best possible piece of equipment, everybody would want it and use it. Instead, increased understanding of consumer needs and desires has lead to the conclusion that different types and models of solar cookers should be available to cater for different market segments and that the use of solar cookers depend on far more than the technical performance of the cooker-for example, is it affordable, is it attractive, do consumers aspire to use the product, is it easily obtainable, is maintenance available? This realisation implies that although there is always room for technical improvement, fiddling with designs should stop and investment diverted to cheaper production processes, marketing costs and end-user finance options, to name but a few.

This article aims to summarise the various solar cooking impact studies and research efforts carried out since the inception of the DME/GTZ solar cooker field test in South Africa in 1996. It should be noted that the different end-user studies employed different methodologies, varied in the level of intensity, length of research and purpose as well as reporting format. A synthesis review of the collected data was carried out on request of GTZ with the aim to firstly, compare solar cooker use rate figures between the different studies to determine if there are large deviations or if the studies, using different methodologies and sample sizes come up with more or less similar use rate figures. Secondly, the synthesis study attempted to identify the important factors influencing solar cooker use rates and changes in solar cooker use rates. It is important to remember that the solar cooker designs changed substantially during the course of the project because of continuous technical interventions, necessitated by the demands of cheap production, material availability and cost. It was therefore, not possible to compare user rates per stoves, since some stove dropped out after the first phase and other change so significantly that comparisons would be of little value. The article is based on the 
findings of the commissioned synthesis study and attempts to provide a summary of solar cooker use rates, factors influencing solar cooker use rates as well as the impact of solar cooker use.

\section{Solar cooking history}

Cooking with the energy of the sun is not a new or novel idea. According to Halacy and Halacy (1992) the first scientist to experiment with solar cooking was a German physicist named Tschirnhausen (1651-1708). He used a large lens to focus the sun's rays and boil water in a clay pot. His experiments were published in 1767 by a Swiss scientist Horace de Sausure who also discovered that wooden "hotboxes" he built produced enough heat to cook fruit. French Scientist Ducurla improved on the hotbox design by adding mirrors to reflect more sunlight and insulating the box. The first book on the subject "Solar Energy and its Industrial Applications” was published by August Mouchot. In 1877, Mouchot designed and built solar cookers for French soldiers in Africa and in 1878 exhibited a solar concentrator at the Paris exhibit. The first recorded solar cooker to be used on South African soil was probably by Sir John Herschel during a scientific expedition to the Cape of Good Hope in 1885. The stove was made out of mahogany, painted black, buried into sand for better insulation and covered by a double glazing to reduce heat losses (GTZ and DME, 2002b, vol. 1).

Increased public interest in solar stoves emerged in the 1950s and 1960s when most of the basic design variants were tried and disseminated. They include the following examples:

- The classic Indian box cooker (fibre reinforced plastic or sheet metal outer casing, aluminium interior casing, double tempered glazing, single glass mirror reflector lid) was developed and tested in many variations, including the use of a light bulb as back-up heat source (GTZ and DME, 2002b, vol. 1).

- Maria Telkes invented the "Telkes cooker”-a box cooker featuring an array of four external reflectors (Stanley, 1993).

- Harry Tabor invented a parabolic concentrator using an array of shaving mirrors (GTZ and DME, 2002b, vol. 1). 
Interest in renewable energy during this period was fuelled by the aftermath of the Second World War with its fuel shortages and rationing, an increased desire to use solar energy "to help people" and as a potential area of investment (Laird, 2005).

Independence gained by former colonial states brought a focus on development and the need to address the "underdeveloped" state of these countries. Lastly, the oil crisis of the early 1970s also contributed to efforts to become less dependant on non-renewable sources of energy. Growing fuel wood and other energy shortages, coupled with expanding populations in China and India, encouraged governmental research on alternatives in the 1970s with China holding its first seminar on solar cooking in 1973 (Knudson, 2004).

Activities the 1980s and 1990s built on earlier efforts at first. China began distributing subsidized cookers in 1981 (Knudson, 2004). The ULOG group in Switzerland, EG Solar in Germany and Solar Cookers International were all founded during the 1980s. The work of Barbara Kerr and Shery Cole resulted in a solar cooker kit that was easy to build by the user and served as foundation for the development of a solar panel cooker by Solar Cookers International, which is still used today (Knudson, 2004).

\section{Motivation for promotion of solar cookers}

Traditionally, solar cookers were seen as a logical solution to the problems associated with fuel wood use. Fuel wood as well as charcoal is ubiquitous fuels in low-income households throughout the world. In the world's energy supply, fuel wood is far more important than nuclear energy (European Committee for Solar Cooking Research, 1995) and more than 3 billion people (GTZ, 1997) use fuel wood to cook worldwide. The picture is not hugely different for South Africa. Domestic consumption of fuel wood in South Africa is estimated at 11 million tons (Mt) or $840000 \mathrm{~m}^{3}$ per annum (Christie and Gandar, 1994). An estimated 13 million people depend on wood as their main source of energy (Deshingar and Cinderby, 1997) and average firewood consumption per person per annum is estimated at 1, 14 tons (Bembridge and Tarlton, 1990). Most of the fuel wood is used for cooking and it is estimated that $95 \%$ of the rural population of South Africa is dependant on fuel wood for cooking (Wentzel, 1996). Traditionally, fuel wood has been regarded as a "free" good harvested from the natural vegetation. 
Overexploitation of the resource is resulting in denudation, environmental degradation and scarcities for households dependant on the fuel. Wilson and Ramphele (1989) provide a thorough overview of area reports dealing with the difficulties of collecting adequate fuel wood - average walking distances to collect wood was between 5.6 and $9.6 \mathrm{~km}$, headloads weighed on average $30 \mathrm{~kg}$ and people moved from collecting dead wood to cutting off green branches or felling trees: "Over the relatively brief span of the past fifty years, 200 of the 250 forests in KwaZulu have disappeared". Karakezi et al. (2004) states that the average wood fuel collection trip in southern Africa is about $6 \mathrm{~km}$ while it can be as long as $10 \mathrm{~km}$ in Eritrea. On average, households make 2-3 collection trips per week. The implication of travelling long distances to collect firewood is that women and girl-children mostly responsible for fuel wood collection, have less time to spend on other activities and are exposed to the threat of wild animals, attack, rape and abduction when travelling far from their homes.

Apart form the clear benefits that can be realised by solar cookers for wood fuel users, increased understanding of household energy use has lead to the conclusion that solar cookers can also benefit users of commercial fuels in terms of monetary savings since it was recognised that general energy shortages in low-income households exist, especially to supply secure and adequate energy for cooking purposes. Solar cookers were therefore, not only viewed as a solution to fuel wood shortages but as a solution for poor households' cooking needs, whether they were experiencing fuel wood-, paraffin-, gas- or electricity shortages - in short, solar cookers were viewed as a mechanism to increase fuel security in low-income households and to broaden choice in terms of energy options available for cooking. This was supported by the view that solar cookers can never be promoted as a single solution to the problem of cooking energy, but that a solar cooker should be viewed as an add-on appliance in a suite of cooking options available as part of the multiple fuel use pattern displayed by low-income households. Tangible, monetary savings served as an important motivator for households to use solar cookers during the DME/GTZ field test and the highest average use rates during phase 1 were recorded in the urban, electrified test area, as illustrated below (Fig. 1): 


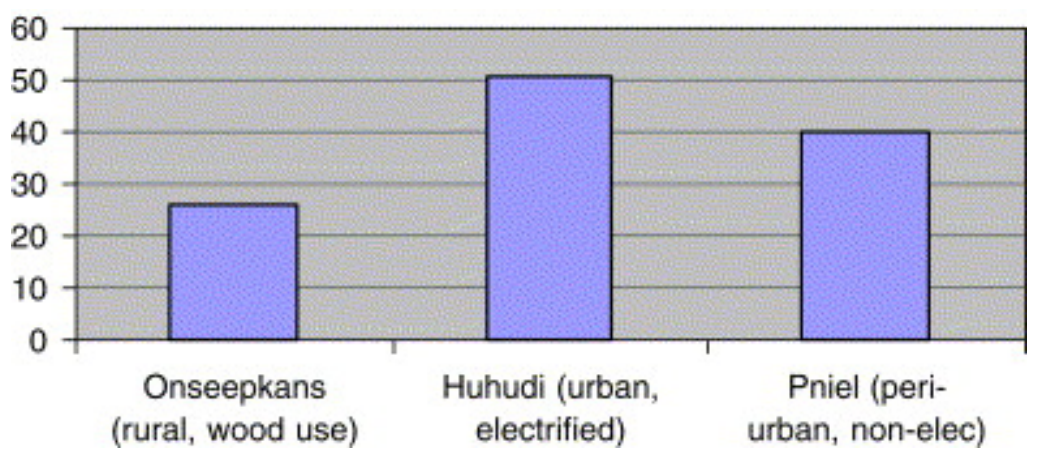

Fig. 1. Solar cooker use in three test areas (Source: GTZ and DME, 2002c, vol. 2). Explanations for the specific use rates were (GTZ and DME, 2002c, vol. 2):

- Monthly energy expenditure was the highest in Huhudi, which also had access to electricity. By using solar stoves regularly, tangible savings in terms of monetary expenses on energy as well as specific expenses on electricity could be achieved. This may have motivated households to use their solar stoves.

- Onseepkans is a very poor area where people cannot afford to cook for every meal. Therefore, cooking opportunities were less than in the more well-off area of Huhudi. - A mixture of commercial fuels and collected wood was being used in Pniel, with monetary savings clearly realised. Moreover, Pniel is slightly better off than Onseepkans and households cooked more often and regularly baked bread in the solar stoves. The motivation to promote solar cookers has therefore, evolved from a desire to alleviate the fuel wood shortages and environmental problems associated with wood fuel use, to the a realisation that solar cookers are actually for anyone requiring energy for cookingnot only for poor households, but also middle - to higher income households and all fuel users, from wood to electricity. The reasons for conducting the solar cooker field test in South Africa were numerous, namely excellent solar radiation for most of the year, staple foods suitable for solar cooking, positive political changes and promising infrastructure in terms of manufacturing and marketing.

\section{The GTZ/DME solar cooker field test in South Africa}

The European Committee for Solar Cooker Research (ECSCR) tested a number of solar cookers in 1994 in Almeria, Spain. The purpose of the test was to ascertain the technical performance capabilities of the equipment, independent of any particular user 
requirements. The results from the test indicated that a number of efficient models were available, and these were included in the selection for the field test in South Africa. Despite the technical advances in solar cookers, it was noted that some technical features were still in need of close attention/improvement.

On the basis of a baseline study carried out in four potential test areas in South Africa, 3 test areas were selected. This included deep rural (Onseepkans on the Namibian border), rural (Pniel, a village near Barkly-west) and peri-urban (Huhudi, township near Vryburg) areas. A total of 100 families made up the test sample, 70 user families (with cookers) and 30 control families without cookers. The test also included 14 institutions, in all cases education centres and in most cases pre-schools. Six solar stove models were placed with families, three models each for large households (more than 4 members) and three models for small families. Every family had one solar stove model for a period of 2 months before changing and using another one. Therefore, by the end of the test period, each family had tried every solar stove twice, enabling comparisons between solar cooker models. At the end of the test period of 1 year, families could purchase the solar cooker of their choice and $73 \%$ of the test families bought a solar cooker. The reasons why not every family bought a cooker was that there were only 20 test cookers per type available and some households could not get the cooker of their choice. The most popular model for small families was the REM5 (a box cooker with external reflectors) and for large families the SK12 (a parabolic reflector cooker). Data was collected through a system of three different questionnaires, daily observation by the local field workers, monthly area visits by members of the project team, in-depth interviews and focus groups The second phase of the programme set out to begin local manufacture of selected solar cookers in South Africa, distribute them through existing sales channels, and sell them in a limited geographical area (the Northern Cape, North-West and Limpopo provinces of South Africa) to a specific target group. The target group was identified as low-tomedium income households experiencing energy shortages for cooking and often dependant on fuel wood as the main cooking energy source. A secondary target group was identified as outdoor enthusiasts, campers or environmentally focussed households (Wentzel, 2003). It should be noted that the main focus of the second and third phases shifted from users to establishing local production, methods of selling solar cookers and 
on-going technical adaptations as necessitated by the demands of finding a high-quality cooker at a low price. As such, user acceptance was not as thoroughly investigated as in the first phase. Data regarding solar cooker purchases, use and impacts were collected through a series of visits to buyers of solar cookers, telephone interviews and posted questionnaires. Purchasers of solar cookers were located through a warranty card system included with every sold solar cooker — the buyer had to complete the card with their contact details as well as details regarding the purchase of the solar stove and mail it back to activate the warranty. The various studies, on which the paper is based, are listed with their relevant sample sizes in Table 1.

Table 1.

End-use studies carried out during the GTZ/DME solar cooker programme

\begin{tabular}{|l|l|l|}
\hline Title & Short description & Sample size \\
\hline $\begin{array}{l}\text { End-user } \\
\text { acceptance } \\
\text { study, phase 1 }\end{array}$ & $\begin{array}{l}\text { A year-long acceptance test were carried out in three selected test } \\
\text { areas, representing different fuel use patters as well as socio- } \\
\text { economic profiles on the basis of a comparative test. User families } \\
\text { had the opportunity to use 4 different types of solar cookers for the } \\
\text { period of 3 months each to enable comparative analysis }\end{array}$ & $\begin{array}{l}100 \\
\text { households }\end{array}$ \\
\hline $\begin{array}{l}\text { Ex-post } \\
\text { purchase } \\
\text { study }\end{array}$ & $\begin{array}{l}\text { The study was completed 3 years after the initial field test, re- } \\
\text { visiting user families from phase 1 who purchased solar cookers } \\
\text { after completion of the field test }\end{array}$ & 43 \\
\hline $\begin{array}{l}\text { End-user } \\
\text { acceptance } \\
\text { study, Phase 2 }\end{array}$ & $\begin{array}{l}\text { Solar cookers were sold through existing sales channels, and in a } \\
\text { limited geographical area (the Northern Cape, North-West and } \\
\text { Limpopo provinces of South Africa) to a specific target group, } \\
\text { identified as low-to-medium income households experiencing } \\
\text { energy shortages for cooking and often dependent on fuel wood as } \\
\text { the main cooking energy source }\end{array}$ & $\begin{array}{l}54 \\
\text { households }\end{array}$ \\
\hline $\begin{array}{l}\text { Market } \\
\text { research } \\
\text { survey, 2003, } \\
\text { part 1 }\end{array}$ & $\begin{array}{l}\text { Survey to determine the awareness and understanding of solar } \\
\text { cooking technology in the low to medium income target group }\end{array}$ & $\begin{array}{l}200 \text { random } \\
\text { interviews }\end{array}$ \\
\hline $\begin{array}{l}\text { Market } \\
\text { research } \\
\text { survey, 2003, } \\
\text { part 2 }\end{array}$ & $\begin{array}{l}\text { A focussed study on owners and users of solar cookers, in } \\
\text { possession of their cookers for 4 years and more }\end{array}$ & 60 \\
\hline
\end{tabular}


At the end of phase 2, the conclusions were that attempts to establish local manufacture, failed and that solar cooker sales were disappointingly low. Reasons for the low sales figures were varied. Firstly, the quality of locally produced cookers was low and erratic, producers were unreliable and material difficult to obtain and the manufacturing process was extremely complex-for example, in one cooker, more than five types of material (steel, glass, fibre glass, aluminium and rubber) had to be used. Secondly, and very importantly, the price of the solar cookers was high and unable to compete with established, well-known and trusted alternative cooking appliances on the market. A paraffin (kerosene) stove which could be bought for a 10th of the price of a solar stove, was available in a variety of outlets and could be repaired if necessary. Apart from price, solar stoves were not widely available since the commercial outlets such as shops, discount retailers and furniture stores which traditionally sell cooking appliances were unwilling to stock and sell solar stoves. This meant that traditional sales channels with additional “perks” such as end-user credit, mass marketing, warranties and an established distribution network were closed to the solar cookers. It was realised that the incredible difficult task of creating a market for a new product required a different approach and the third and last phase of the programme called on the expertise of business, marketing and distribution experts with the realisation that to commercialise solar cookers, an entire industry needs to be created to service the proven existing demand, as illustrated by Market Research Africa (2003). It should be noted that the conclusion did not question the viability of the technology nor end-user acceptance thereof: it was the inability of the market to deliver products at the right price, place and time that was the deemed to be the cause for failure. This is an important distinction: solar cooker sales were low, mainly because they were expensive and not widely available but where people did cross the hurdle and actually made a purchase, the solar cooker was well used (on average 31\% of the household's cooking incidences).

The following end-user focussed studies were carried out throughout the course of the project: (Table 1)

Two further studies contained some use rate information and were used in the broader analysis: 
- A report on solar cooker use in Kenyan refugee camps, prepared by GTZ and UNHCR (GTZ and UNHCR, 2004);

- A report on solar cooker use in Osire refugee camp in Namibia (GTZ, 2005).

\section{The development impact of solar cookers}

Solar cooking investigations and activities have been ongoing in South Africa since the 1970s. An early pioneer of solar cooking, Willi Suremann manufactured solar cookers based on a model developed by the Canadian Brace Research Institute and in the 1980s the then KwaNdebele Parks Board purchased 12 large and 12 small solar cookers from him (Wentzel, 1997). A solar energy project at the Canadian-funded Thaba Tseka rural development programme developed, built, manufactured and disseminated solar ovens in an attempt to meet the need for scarce cooking fuel (Eberhard, 1984). Eberhard (1984) concluded that the lack of successful adoption of the solar cookers by the target population was attributed to the fact that the introduction of the technology was born out of a need as perceived by project personnel rather than a demand expressed by local villagers. During 1991, a version of the Solar Cooker International Cookit was introduced through a series of community workshops in the Free State Province. Apart from the report by Eberhard (1984), limited data exist on the early success and failures of introducing solar cooking into South Africa.

The GTZ/DME solar cooker field test generated significant amounts of data and based on existing data sources some form of evaluation of the potential development impact of solar cookers can be attempted.

\subsection{Solar cooker use rates}

Solar cooker use rate is defined as the number of times a household opts to use a solar cooker (either on its own or in conjunction with other fuels) to cook food, therefore the use rate percentage refers to the number of times a solar cooker was used out of all the household cooking incidences. It should be noted that households do not cook 3 times per day. At least 5 different studies investigated solar cooker use rates since 1996 in South Africa (Palmer Development Group, 1997a and Palmer Development Group, 1997b; Synopsis and Palmer Development Consulting, 2000; Palmer Development Consulting, 
2002a and Palmer Development Consulting, 2002b; Market Research Africa, 2003 and Kitzinger, 2004).

In summary, the studies consulted reflected varying solar cooker use rates (Table 2): Table 2.

Average use rates from consulted studies

\begin{tabular}{|l|l|}
\hline Study name and date & $\begin{array}{l}\text { Average } \\
\text { use rate } \\
\text { (\%) }\end{array}$ \\
\hline $\begin{array}{l}\text { Solar Cooker Field Test in South Africa. End-user acceptance. Phase 1, Main Report, } \\
\text { vol. 1 (1997) }\end{array}$ & 38 \\
\hline Long-term household acceptance of solar cookers. Ex-post purchase evaluation (2000) & 31 \\
\hline $\begin{array}{l}\text { Internal report prepared for GTZ evaluation mission. Additional inquiries into use } \\
\text { rates (2002) }\end{array}$ & 34 \\
\hline Profile of solar cooker purchaser. First telephone interview (2002) & 33 \\
\hline $\begin{array}{l}\text { Overview of solar cooker use rates and durability. Final Report to CEF/EDC. Latest } \\
\text { telephone interview (2004) }\end{array}$ & 33 \\
\hline Market Research Africa study for business case (2003) & \\
\hline
\end{tabular}

If the average reported use rates for the various studies are accepted, an average use rate of $31 \%$ is indicated. The standard deviation was $5.6 \%$. Therefore, if it is accepted that solar cooker use rates are over-reported as is often suspected, rather than under reported, solar cooker use rates can be accepted to be between 31\% and 25\%. The confidence interval of $95 \%$ indicates that it can be $95 \%$ sure that use rates are between $37.67 \%$ (average plus standard deviation) or 25.67\% (average minus standard deviation). Many factors influence solar cooker use rates and a change in use rates:

\subsubsection{External conditions}

External conditions influencing use rates are for example, weather conditions (strong wind, rain, cloud cover and general lack of sunshine), limited space to use the stove, 
moving house resulting in lack of space to use the cooker, lack of storage space and lack of adequate security when cooking is taking place, placing the cooker and the food at risk. The lack of food to cook as well as management strategies using uncooked, prepared food such as bread, tinned fish and eating cold left over food also influences the number of times a solar cooker is used.

\subsubsection{Change in interest}

Respondents cited the fact that they became too lazy to use the stove, they became bored with it (in line with a novelty purchase), a change in cooking patters or habits made them stop using the stove and that they found the process too cumbersome. Other cases were found where people had bought a solar cooker but have not started using it because they forgot about it, are unsure how to use it but report that they will try to use it in future.

\subsubsection{Stove characteristics}

Users sited problems with their solar stoves as an important reason for reduced use or stopping to use them entirely - the stove is too slow, the break is faulty, there is only one pot, there is no baking tray, etc. The Kenyan study (United Nations High Commission for Refugees (UNHCR), 2004) noted the fact that badly assembled stoves, lost and unavailable spare parts such as wing nuts and reflector blades also hampered acceptance. Most importantly though, is that the stove capacity is inadequate (meals have to be prepared for a large number of people and the pot or pots are too small). The Kenyan study also adequately shows that if a solar cooker cannot be used to prepare traditional staple dishes, use will be limited.

\subsubsection{Lack of black cooking pots}

The importance of selling the cooker with a black pot has been stressed since the inception of the solar cooker field test in South Africa. The project team felt so serious about including good quality black pots that it was considered to market the solar cooker as "buy a black pot and receive a solar cooker for free”. The Kenyan study (UNHCR, 2004) concluded that it is vital to have a properly painted black pot. A comparative water boiling test was carried out with an aluminium pot painted black vs. an unpainted pot of 
the same type and it was found that it took an average of 30\% longer to boil water using the latter. A number of observations were made regarding under-performance of the cookers arising from pots from which the paint had been rubbed off, poorly fitting lids supplied by the pot manufacturer and inadequate size of the pots for institutional use. From the Market Research Africa study (2003), 11\% of non-users stated the lack of black pots as the reason for not using their solar cooker.

Four of the studies consulted yielded information on the percentage of users who are no longer using their solar stoves. Available data indicated that on average, $17 \%$ of purchasers/owners of solar stoves stop using them after about 1.5 years after purchase.

\subsection{Savings associated with solar cooker use}

To determine solar cooker use rates and resulting energy savings is a notorious difficult task. User behaviour is influenced by a number of aspects, fluctuate over time and quite simply can often not be adequately explained; for example, a solar stove buyer in Huhudi was struggling with her stove payments, had only used the stove about 3 times in 6 months but was completely unwilling to give up the stove and have her money returned since she felt strongly that she will use the stove in future.

\subsubsection{Fuel savings}

Table 3 provides the results for the corresponding total average (over all users and all fuel types), during the first phase of the solar cooker field test, stating that the overall fuel savings were 38\%. During the placement period, test users saved almost 60 tons of wood, more than 2 tons of gas, and over 2000 L of paraffin (GTZ and DME, 2002a). 
Table 3.

Average savings for all fuels by households

\begin{tabular}{|l|l|l|}
\hline & Savings (\%) & Weight \\
\hline Paraffin & 33 & 0.28 \\
\hline Gas & 57 & 0.16 \\
\hline Wood & 36 & 0.56 \\
\hline Unweighted total average & 42 & - \\
\hline Weighted total average & 38.4 & - \\
\hline
\end{tabular}

Source: Solar Cooker Field Test (2002, vol. 2).

Individual fuel savings can also be seen in Table 3 with the highest percentage savings achieved for gas (57\%), wood (36\%) and paraffin (33\%) in descending order.

User studies during phase 2 (Palmer Development Consulting, 2002a and Palmer Development Consulting, 2002b) indicated that the fuel most saved by households using their solar stoves was electricity, followed by gas and then paraffin. The majority of respondents reported in the sample some form of fuel savings.

\subsubsection{Monetary savings}

The results for the average monetary savings during the first phase of the field test (Solar Cooker Field Test in South Africa. End-user acceptance. Phase 1, Main Report, vol. 1, 1997) were not homogeneous for the three test areas. Savings were highest in Huhudi, where fuels are mostly bought and the township is electrified, and lowest in Onseepkans, where collected wood is an important fuel source. Pniel with its intermediate fuel mix falls in-between. For details see Table 4. 
Table 4.

Average monetary savings by households in the three test areas

\begin{tabular}{|l|l|l|l|}
\hline Indicator & Pniel & Onseepkans & Huhudi \\
\hline Weighted average all fuel saving (\%) & 36 & 40 & 39 \\
\hline Average monthly fuel expense (ZAR) & 46 & 31 & 66 \\
\hline Average monthly fuel savings (ZAR) & 17 & 12 & 26 \\
\hline
\end{tabular}

Source: Solar Cooker Field Test (2002, vol. 2).

The phase 2 end-user report (Palmer Development Consulting, 2002a and Palmer

Development Consulting, 2002b) found that 28 out of 54 respondents reported monetary savings $-52 \%$ of the sample. On average, respondents reported monthly savings of R110. It is often difficult for respondents to know exactly how much they are saving and of the 28 respondents reporting savings, seven could not quantify the savings. During the first phase of the Solar Cooker Field Test (Palmer Development Group, 1997a and Palmer Development Group, 1997b) savings were reported between R20 and R100 with an average monthly saving of R45. The higher savings of R110 were achieved because of respondents using more commercial fuels than the sample saving only R45-they relied on wood fuel that is collected and not bought.

The ex-post purchase study (Synopsis and Palmer Development Consulting, 2000) did not investigate savings specifically, but when asked why respondents had bought a solar cooker (independent of the model); the most cited reasons were monetary savings in fuel expenses and convenience (time savings, unattended cooking and having an additional “fuel” source) (Table 5): 
Table 5 .

Reasons for solar cooker acquisition

\begin{tabular}{|l|l|}
\hline Reason & Entries \\
\hline Savings & 44 \\
\hline Convenience & 29 \\
\hline Other & 13 \\
\hline
\end{tabular}

Source: Synopsis and Palmer Development Consulting (2000).

The investigation conducted by Market Research Africa (2003) also did not record specific savings (energy, monetary or time) although it was reported that users were motivated by cost savings/energy to cost purchase their solar cookers. Free energy, cost savings and no fuel costs were the most important perceived advantages of solar cookers. In summary, from the studies containing reports on savings, the majority of solar stove owners reported savings, while the average reported monthly savings between the three studies was R68. It is often difficult for users to estimate savings achieved through the use of a solar cooker since savings depend on a wide variety of issues such as fuel use, frequency of cooking and type of food cooked. For example, in a household were multiple-fuel use is the norm, it becomes difficult to estimate how much of each fuel is saved, since the solar cooker displaces a little of each fuel used by the household. Although monetary savings of R68 (approximately \$11) may not seem significant, viewed against the background of low-household income and poverty, savings are highly valued by users earning an average monthly income of R600 or about $\$ 100$ per month.

\subsubsection{Time savings}

Since it is mainly women who do the cooking in the household, it is mainly their time that is being saved by using a solar cooker. There are two potential time saving elements associated with the use of a solar cooker:

- Time savings which results from the reduction in wood gathering;

- Potential time-savings in the actual cooking process. 
Although most solar stoves cook slower than other stoves, they require very little attention once the food is in the stove. Freed from the time-consuming tasks of cooking and wood collection, women may concentrate more on childcare and domestic activities, training and educational programmes, social networking (an important rural livelihood strategy), as well as leisure (Palmer Development Group, 1997a and Palmer Development Group, 1997b). Where children are the main wood gatherers, time saved can be spent on schoolwork or play.

During the first phase of the programme, time saved from reduced wood collection because of solar cookers was calculated as 36\% of the normal wood fuel collection time as recorded in the baseline study (Solar Cooker Field Test in South Africa. End-user acceptance. Phase 1, Main Report, Volume 1).

During the first telephone interviews (Palmer Development Consulting, 2002a and Palmer Development Consulting, 2002b), saving time by using a solar cooker was reported by $44 \%$ of the respondents. On average, respondents reported saving between 18 and $26 \mathrm{~h}$ per month by using a solar stove. Time saved is influenced by a variety of factors such as the type of fuel being used, the length of time they would normally cook on their stove or open fire (which also depends on the type of food cooked) and how many meals are cooked per month.

\subsubsection{Impacts on poverty reduction}

The economic benefits associated with time-savings can be significant if the time is spent on productive, income generating activities. Since it is primarily women who are involved in cooking and woodfuel collection, the potential for economic benefits depends on the opportunities available for increasing earnings and output. The impact of solar stoves on the household economy is dependant on the organisation of the household economy and the extent to which the household is linked to the wider economic network. In two of the original test areas (Pniel and Onseepkans), solar cookers became a valuable resource for social networks, as information on solar cookers and the preparation of food was exchanged. Savings achieved through the use of the solar stoves were invested in more food, which were shared amongst the organised cooking groups. These cooking 
groups increased food security as well as variety in the daily diet. Other economic benefits observed can be summarised as:

- Money saved was given to schools;

- Increased contributions to churches was recorded;

- Other organisations such as women's groups, savings clubs and clinics benefited from household savings;

- In Onseepkans, time saved became increased labour time for subsistence agriculture;

- In Pniel, increased time and increased savings was spent on transport to enable greater access to centres seeking job opportunities;

- In Huhudi, hawkers saved money to buy fuel and food to sell.

Phase 2 (Palmer Development Consulting, 2002a and Palmer Development Consulting, 2002b) confirmed the potential development impacts of phase 1 (End-user acceptance study, 1997). Respondents reported that time savings were utilised in some productive activities while monetary savings were used for school fees, improved food stuffs such as vegetables and meat. De Lange and Wentzel (2002) noted that solar stoves improve household energy availability, which in turn can reduce poverty and improve quality of life. Solar stoves were found to improve household energy availability in the following ways:

- In poorer households where a larger percentage of monthly income is spent on fuels, more money is available for buying other fuels, thereby enlarging the fuel mix available for the household;

- Besides enlarging the fuel mix, solar stoves also increase energy security. Once the household owns a solar stove, they will always be able to cook (as long as the sun is shining);

- Money saved, which would have been spent on energy, is now available for other things;

- By cooking with a solar stove, fossil fuels or electricity are available for other activities or energy end-uses. For example, instead of using paraffin for cooking, it can be used for lighting;

- Foods that require a long cooking time use a lot of fuel, so they are ideally suited for solar cooking (e.g. maize porridge, soup, beans, samp and baking bread) are the most 
important staple foods in South Africa and being in a position to cook the staple dish without being concerned about the amount of fuel to be used in the cooking process was experienced as positive.

\subsubsection{Income generation potential of solar cookers}

During the course of the DME/GTZ solar cooker field test, attempts were made to determine if solar cookers can have an income-generating function. However, since income generation was never a primary focus of the programme, activities were never undertaken on a large scale and the recorded evidence of solar cookers used for income generation is therefore scant. The first example was during the year-long field test when one of the large solar cookers was placed with Mrs Sebola, a tavern/shebeen owner in Huhudi (Palmer Development Group, 1997a and Palmer Development Group, 1997b). She used the cooker to prepare meals, which she sold in her shebeen, the main business of which was selling beer. As a businesswoman she immediately realised that she was saving money with the use of her solar cooker and she was the only person in the field test to opt to spend R1000 to buy the cooker at the end of the test period.

During the second phase of the programme, an agreement was reached with the Taxi Association in Rustenburg whereby a number of street hawkers/vendors who sell food at taxi ranks tested the use of solar cookers in their businesses. In total 3 hawkers participated but the solar cookers were found to be of limited use to them in their foodselling business (GTZ, 2001). Despite the fact that the hawkers immediately understood the energy savings associated with the use of a solar cooker, the following factors made it difficult to fully incorporate the use of a solar cooker in their daily selling activities:

- Solar cookers were not suited to the type of foods that the hawkers prepared, for example fried sausages and deep-fried vetkoek, because solar cookers can not reach temperatures high enough to deep fry food;

- Hawkers require a high turn over of food to supply their customers and the solar cookers were experienced as too slow to supply the dishes in the required time;

- The capacity of the solar cookers were found to be too small and the fact that a solar cooker can only use one pot at a time (especially the fast parabolic cooker) made it difficult for hawkers to prepare the volume of food required; 
- Solar cookers are bulky devices and not easily transported via public transport, the mode of transport that the hawkers have to rely on;

- The solar cookers could not be left at the taxi rank since there was no storage space available that the hawker could use.

At the end of the study, the hawkers agreed that although solar cookers may be a good idea, they were not really appropriate for their businesses and the field test concluded that solar cookers have a limited potential to be used by street vendors for income generation purposes. Outside the field test, limited activities have explored the potential of using solar cookers for income generation purposes. One example is a solar powered bakery established in the Eastern Cape by Sun Ovens International. A village size Sun Oven with LPG back-up was installed to employ HIV positive women to bake bread (SCI, 2004). The project was reported to be functioning well, although no further information was published.

\section{Conditions promoting the use of solar cookers}

Studies have indicated a number of conditions conducive to solar cooker use. Three main categories of conditions have been identified:

\subsection{External or environmental conditions}

Solar cookers have generally been promoted in areas where fuel wood shortages are experienced such as rural areas and refugee camps. However, results from the GTZ/DME field test indicated highest user rates in an electrified area and subsequent sales were mostly to electricity users. Although fuel wood shortages may be an important pushfactor to promote the use of solar cookers, the cost and scarcity of commercial fuels can also convince users to take up the technology. External conditions which can promote the use of solar cooking are therefore, the general lack of adequate energy sources and a desire to achieve savings (time or monetary) by end-users.

At the household level, certain external factors can promote the uptake or refusal of solar cookers:

- Adequate storage space for the solar cooker: Users viewed solar cookers as investments and were reluctant to store cookers outside. The lack of safe and protected storage space 
inside, influenced Phase 1 users to opt for smaller cookers which could be easily stored while schools without adequate storage space decided not to purchase a cooker at all; - Yard space and availability of a sunny place for cooking: In some urban areas houses are very close to each other and yards may not have adequate sunshine due to tall trees and vegetation or shadows form neighbouring buildings. Information brochures during the field test recommended users to make sure that there is an outside spot where the cooker will be in the sun for $3 \mathrm{~h}$ at a time;

- While security issues (theft of cookers or food from cookers) are often mentioned as potential deterrents, security issues were not noted to be problematic during the field test. Having someone at home while using the cooker was mentioned as an advantage, but this was not because of fear of theft, but to enable orientation of the cooker. Although security issues may be problematic in different societies, it was not experienced as a problem in the South African case.

\subsection{User conditions}

Important aspects concerned with the user of a solar cooker were identified:

- There must be adequate motivation to use the cookers. Potential savings were the most important motivation mentioned by users to purchase and use their solar cookers while an element of curiosity was also found to be conducive to encourage the purchase of a solar cooker. Male buyers reported curiosity as the most important motivational aspect while women reported potential savings (Palmer Development Consulting, 2002a and Palmer Development Consulting, 2002b).

- Successful solar cooking requires a basic a form of training and being exposed to a solar cooking demonstration was rated highly by users to ensure cooking success and therefore on-going use. A variety of instruments were used to inform users how to use their solar cookers successfully, for example, pamphlets, user instructions, brochures and recipe books were distributed with the cookers (GTZ and DME, 2002a) while approximately 500 wet demonstrations were carried out throughout the implementation period (GTZ and DME, 2002a).

- Using solar cookers requires adaptation mostly in terms of kitchen management. Planning ahead and preparing food becomes important—you cannot decide to solar cook 
a chicken stew $1 \mathrm{~h}$ before mealtime. Once solar cookers are integrated in the process of kitchen management and cooking, users chose to use them regularly as indicated by an average use level of $31 \%$.

\subsection{Technical conditions of solar cookers}

The price of solar cookers was found to be one of, if not the most important issue in promoting the use of solar cookers. Solar cookers were expensive in the field test for a number of reasons such as low production numbers, no critical mass, purchasing of small quantities of material due to low production runs, high material prices, and the high cost of distribution and transport. Solar cookers as well as energy efficient cooking appliances have to compete with well-known and cheap cooking appliance alternatives in the market. A solar cooker is a largely unknown device to a consumer, and therefore, represents an investment risk-I am not sure if this thing will actually work, therefore it is difficult for me to invest 10 times as much as I would have spent on replacing my existing cooking appliance. The project did not introduce any form of end-user finance but instead, in keeping with the commercialisation focus of the project, attempted to convince established banks and credit organisations to extend end-user credit for the solar cookers. This was a failure because of low confidence in the device as well as the difficulties of financing a small, moveable object.

Although it may seem superfluous, it is important to note that for solar cookers to be used successfully, the cooker must be functional, efficient, durable, attractive and user friendly. Too often, solar cookers look as if they were assembled in a back yard by an unskilled labourer. Even poor consumers demand high-quality products and rightly sothey have to spend scarce and hard earned money on an unknown product and the purchase therefore represents some risk to them. Solar cookers need to move beyond the image of an appropriate technology product, towards a highly desirable product. Attention therefore, needs to be paid to product design, finish, packaging and marketing.

\section{Conclusions and recommendations}

Despite the failure of the programme to achieve large-scale commercialisation and local production of solar cookers in South Africa, households using solar cookers reported 
quantifiable benefits. Strong evidence emerged from all the studies that the users of solar cookers experience savings. It should be noted that the average saving of R68 found may be under reported as it is often difficult for users to estimate savings achieved through the use of a solar cooker since savings depend on a wide variety of issues such as fuel use, frequency of cooking and type of food cooked. Evidence from recorded fuel, monetary and time-savings as well as the noted development impacts, especially for women therefore, indicate that the use of solar cookers does have positive development impacts at the household level.

From the point of view of establishing solar cookers as a commercial venture in South Africa, the programme failed. The failure of the programme cannot be attributed to one specific reason only_-solar cookers are not widely used due to factors associated with the technology (the cookers themselves), the price of the cookers, the users and the environment in which they are used. However, evidence also indicate that where solar cookers have been purchased or obtained (gift, inheritance or supplied by an employer for example), solar cookers are used almost a quarter of the time of household cooking incidences. The hurdle therefore, does not seem to be to convince someone to use a solar cooker, but to convince someone to buy a solar cooker. Due to the low awareness regarding solar cookers and their relatively high prices in comparison with established appliances, a solar cooker purchase represents a fair risk, especially to low and middleincome households.

Recommendations to expand the use of solar cookers are as follows:

- Promote solar cookers as an additional cooking option and not as a replacement of conventional cooking fuels and appliances;

- Solar cookers should be sold or promoted as part of an integrated package to address household cooking problems. The package should consist of a fuel efficient stove, a heat retention device and a solar cooker;

- Solar cookers should be well-made products, comparable to other household cooking appliances. The product must instil confidence in the user and be well made, finished and packaged;

- Users must be well supported with information as well as technical back-up in the form of product guarantees. Demonstrations are key to solar cooker sales, since most people do 
not believe that a solar cooker can actually cook. Guarantees provide user confidence in the product and makes the technology more trust worthy;

- Solar cookers should be widely available in shops and outlets where households normally purchase cooking appliances. Transport and distribution of solar cookers proved to be one of the most difficult challenges during the field test and limited availability of cookers impacted negative on sales;

- End-user finance mechanisms through normal credit channels or tailor-made microfinance options are essential to enable very poor households to purchase solar cookers. Without access to credit, solar cookers will not reach the poorest segments of the market, and the households that need them most.

The potential positive environmental impact of solar cookers has not been adequately researched. Since solar cookers replace a variety of fuels, calculating $\mathrm{CO}_{2}$ and other savings resulting form their use is a complex task. Further research is required to develop an acceptable methodology to gauge solar cooker use rates without costly, longitudinal monitoring studies.

\section{References}

Bembridge and Tarlton, 1990 T.J. Bembridge and J.E. Tarlton, Woodfuel in Ciskei. A headload study, South African Forestry Journal (1990) (154), pp. 88-95.

Christie and Gandar, 1994 S. Christie and M. Gandar, Commercial and Social Forestry Draft Position Paper for the Land and Agricultural Policy Centre Project in Natural Resource Management, LAPC, Johannesburg (1994).

De Lange and Wentzel, 2002 E. De Lange and M. Wentzel, Harnessing solar stove technologies in South Africa to promote improved household energy provision, Boiling Point (2002) (48).

Deshingar and Cinderby, 1997 P. Deshingar and S. Cinderby, Renewable Natural Resource Use in Post-apartheid South Africa, Stockholm Environmental Institute (ESI), Stockholm (1997).

Eberhard, 1984 A.A. Eberhard, Dissemination of solar ovens in lesotho: problems and lessons, Proceedings of the Eighth Biennial Congress of the International Solar Energy Society, Pergamon Press, New York (1984). 
European Committee for Solar Cooking Research, 1995 European Committee for Solar Cooking Research, Second International Solar Cooker Test. Summary Results, ECSCR, Germany (1995).

GTZ, 1997 GTZ, Solar Cooker Field Test in South Africa. A Comparative Field Test for the Socio-acceptability of Seven Different Types of Solar Cookers, GTZ, Pretoria (1997). GTZ, 2001 GTZ, Marketing of Solar Stoves and the Informal Sector. Solar Cooker Field test Phase II, GTZ, Pretoria (2001).

GTZ, 2005 GTZ. 2005. Evaluation of Solar Cooker Use Rates in Osire Refugee Camp, Namibia. GTZ, Frankfurt.

GTZ and DME, 2002a GTZ and DME, Solar Cooking Compendium. Challenges and Achievements of the Solar Cooker Field Test in South Africa, GTZ, Pretoria (2002). GTZ and DME, 2002b GTZ and DME, Solar Cooker Compendium Volume 1. Scarcity of Household Energy and the Rationale of Solar Cooking, GTZ, Pretoria (2002). GTZ and DME, 2002c GTZ and DME, Solar Cooker Compendium Volume 2. Social Acceptance of Solar Cookers in South Africa, GTZ, Pretoria (2002).

GTZ and UNHCR, 2004 GTZ and UNHCR, Solar Cooker Evaluation Kakuma and Dadaab, UNHCR, Kenya (2004).

Halacy and Halacy, 1992 B. Halacy and C. Halacy, Cooking With the Sun, Jack Howel, Lafayete, CA (1992).

Karakezi et al., 2004 S. Karakezi, J. Wangeci and E. Mayara, Sustainable Energy Consumption in Africa UN-DESA Report, Afrepren, Nairobi, Kenya (2004).

Kitzinger, 2004 X. Kitzinger, Solar Cooker Usage and Lifetime of Solar Cookers in the Three Pilot Regions Huhudi, Pniel and Onseepkans Field report. Internal report, GTZ, Pretoria (2004).

Knudson, 2004 B. Knudson, State of the Art of Solar Cooking: A Global Survey of Practices \& Promotion Programs, SCI, Sacramento (2004).

Laird, 2005 F. Laird, The society whose time had come, Solar Today July/August (2005), pp. 36-39.

Market Research Africa, 2003 Market Research Africa, Profile of Solar Cooker Purchasers Management report, GTZ, Pretoria (2003). 
Palmer Development Consulting, 2002a Palmer Development Consulting, End-user Monitoring Report. DME/GTZ Solar Cooker Field Test in South Africa, Department of Minerals and Energy Pretoria (2002).

Palmer Development Consulting, 2002b Palmer Development Consulting, Internal Report Prepared for GTZ Evaluation Mission. Additional Inquiries into Use Rates Internal GTZ report (2002).

Palmer Development Group, 1997a Palmer Development Group, Solar Cooker Field Test in South Africa. End-user acceptance Phase 1, Main Report, Volume 1, GTZ, Pretoria (1997).

Palmer Development Group, 1997b Palmer Development Group, Gender Review of the GTZ/DME Solar Cooker Field Test, GTZ, Pretoria (1997).

Shrestha et al., 2005 R.M. Shrestha, S. Kumar, S. Martin and T. Urmee, Application of productive uses pf renewable energy for small, medium and micro-enterprises, Asian Institute of Technology, Thailand (2005).

Solar Cookers International, 2004 Solar Cookers International. 2004. Solar Cooker Review 10(2).

Stanley, 1993 A. Stanley, Mother's and Daughters of Invention: Notes for a Revised History of Technology, Scarecrow Press, Meutchen, NJ (1993).

Synopsis and Palmer Development Consulting, 2000 Synopsis and Palmer Development Consulting, Long-term Household Acceptance of Solar Cookers. Ex-post Purchase Evaluation Study (2000).

United Nations High Commission for Refugees (UNHCR), 2004 United Nations High Commission for Refugees (UNHCR), Solar Cooker Evaluation in Kakuma and Dadaab, UNHCR Technical Support Centre, Dadaab (2004).

Wentzel, 1996 M. Wentzel, Solar cooking: exploring the possibilities and limitations, Journal of Energy in Southern Africa August (1996), pp. 85-88.

Wentzel, 1997 M. Wentzel, Inquiry into Solar Cooking Activities in South Africa prior to 1996 Final Report, Department of Minerals and Energy, Pretoria (1997).

Wentzel, $2003 \mathrm{M}$. Wentzel, A gender profile of solar stove buyers and users: findings from the second phase of the GTZ/DME solar cooker field test programme, Energia News 6 (2003) (1). 
Wilson and Ramphele, 1989 F. Wilson and M. Ramphele, Uprooting poverty: the South African challenge Report for the second Carnegie Inquiry into Poverty and Development in South Africa, David Philip, Cape Town (1989) www.kozon.org).

\section{Further reading}

Bennet, M., 2004. Personal communication. (Margaret Bennet is the director of the Sunstove Organisation, selling the Sunstove solar box cooker in South Africa).

GTZ and DME, Solar Cooker Compendium Volume 4. Marketing Solar Stoves in South Africa, GTZ, Pretoria (2002).

Palmer Development Consulting, 2004. Overview of Solar Cooker Use Rates and Durability Final Report to CEF/EDC.

Bembridge and Tarlton, 1990 T.J. Bembridge and J.E. Tarlton, Woodfuel in Ciskei. A headload study, South African Forestry Journal (1990) (154), pp. 88-95.

Christie and Gandar, 1994 S. Christie and M. Gandar, Commercial and Social Forestry Draft Position Paper for the Land and Agricultural Policy Centre Project in Natural Resource Management, LAPC, Johannesburg (1994).

De Lange and Wentzel, 2002 E. De Lange and M. Wentzel, Harnessing solar stove technologies in South Africa to promote improved household energy provision, Boiling Point (2002) (48).

Deshingar and Cinderby, 1997 P. Deshingar and S. Cinderby, Renewable Natural Resource Use in Post-apartheid South Africa, Stockholm Environmental Institute (ESI), Stockholm (1997).

Eberhard, 1984 A.A. Eberhard, Dissemination of solar ovens in lesotho: problems and lessons, Proceedings of the Eighth Biennial Congress of the International Solar Energy Society, Pergamon Press, New York (1984).

European Committee for Solar Cooking Research, 1995 European Committee for Solar Cooking Research, Second International Solar Cooker Test. Summary Results, ECSCR, Germany (1995).

GTZ, 1997 GTZ, Solar Cooker Field Test in South Africa. A Comparative Field Test for the Socio-acceptability of Seven Different Types of Solar Cookers, GTZ, Pretoria (1997). 
GTZ, 2001 GTZ, Marketing of Solar Stoves and the Informal Sector. Solar Cooker Field test Phase II, GTZ, Pretoria (2001).

GTZ, 2005 GTZ. 2005. Evaluation of Solar Cooker Use Rates in Osire Refugee Camp, Namibia. GTZ, Frankfurt.

GTZ and DME, 2002a GTZ and DME, Solar Cooking Compendium. Challenges and Achievements of the Solar Cooker Field Test in South Africa, GTZ, Pretoria (2002). GTZ and DME, 2002b GTZ and DME, Solar Cooker Compendium Volume 1. Scarcity of Household Energy and the Rationale of Solar Cooking, GTZ, Pretoria (2002).

GTZ and DME, 2002c GTZ and DME, Solar Cooker Compendium Volume 2. Social Acceptance of Solar Cookers in South Africa, GTZ, Pretoria (2002).

GTZ and UNHCR, 2004 GTZ and UNHCR, Solar Cooker Evaluation Kakuma and Dadaab, UNHCR, Kenya (2004).

Halacy and Halacy, 1992 B. Halacy and C. Halacy, Cooking With the Sun, Jack Howel, Lafayete, CA (1992).

Karakezi et al., 2004 S. Karakezi, J. Wangeci and E. Mayara, Sustainable Energy Consumption in Africa UN-DESA Report, Afrepren, Nairobi, Kenya (2004).

Kitzinger, 2004 X. Kitzinger, Solar Cooker Usage and Lifetime of Solar Cookers in the Three Pilot Regions Huhudi, Pniel and Onseepkans Field report. Internal report, GTZ, Pretoria (2004).

Knudson, 2004 B. Knudson, State of the Art of Solar Cooking: A Global Survey of Practices \& Promotion Programs, SCI, Sacramento (2004).

Laird, 2005 F. Laird, The society whose time had come, Solar Today July/August (2005), pp. 36-39.

Market Research Africa, 2003 Market Research Africa, Profile of Solar Cooker Purchasers Management report, GTZ, Pretoria (2003).

Palmer Development Consulting, 2002a Palmer Development Consulting, End-user Monitoring Report. DME/GTZ Solar Cooker Field Test in South Africa, Department of Minerals and Energy Pretoria (2002).

Palmer Development Consulting, 2002b Palmer Development Consulting, Internal Report Prepared for GTZ Evaluation Mission. Additional Inquiries into Use Rates Internal GTZ report (2002). 
Palmer Development Group, 1997a Palmer Development Group, Solar Cooker Field Test in South Africa. End-user acceptance Phase 1, Main Report, Volume 1, GTZ, Pretoria (1997).

Palmer Development Group, 1997b Palmer Development Group, Gender Review of the GTZ/DME Solar Cooker Field Test, GTZ, Pretoria (1997).

Shrestha et al., 2005 R.M. Shrestha, S. Kumar, S. Martin and T. Urmee, Application of productive uses pf renewable energy for small, medium and micro-enterprises, Asian Institute of Technology, Thailand (2005).

Solar Cookers International, 2004 Solar Cookers International. 2004. Solar Cooker Review 10(2).

Stanley, 1993 A. Stanley, Mother's and Daughters of Invention: Notes for a Revised History of Technology, Scarecrow Press, Meutchen, NJ (1993).

Synopsis and Palmer Development Consulting, 2000 Synopsis and Palmer Development Consulting, Long-term Household Acceptance of Solar Cookers. Ex-post Purchase Evaluation Study (2000).

United Nations High Commission for Refugees (UNHCR), 2004 United Nations High Commission for Refugees (UNHCR), Solar Cooker Evaluation in Kakuma and Dadaab, UNHCR Technical Support Centre, Dadaab (2004).

Wentzel, 1996 M. Wentzel, Solar cooking: exploring the possibilities and limitations, Journal of Energy in Southern Africa August (1996), pp. 85-88.

Wentzel, 1997 M. Wentzel, Inquiry into Solar Cooking Activities in South Africa prior to 1996 Final Report, Department of Minerals and Energy, Pretoria (1997).

Wentzel, 2003 M. Wentzel, A gender profile of solar stove buyers and users: findings from the second phase of the GTZ/DME solar cooker field test programme, Energia News 6 (2003) (1).

Wilson and Ramphele, 1989 F. Wilson and M. Ramphele, Uprooting poverty: the South African challenge Report for the second Carnegie Inquiry into Poverty and Development in South Africa, David Philip, Cape Town (1989) www.kozon.org).

Corresponding author. Tel.: +27 12349 2269; fax: +27 123491735 .

${ }^{1}$ Tel.: +27 12420 3843; fax: +27 123625092. 